\title{
Concept of "smart" oil storage facility for agricultural purposes
}

\author{
Stanislav Nagornov ${ }^{1,2^{*}}$, Maksim Levin ${ }^{1,2}$, and Ekaterina Levina ${ }^{3}$ \\ ${ }^{1}$ All-Russian Scientific Research Institute for the Use of Machinery and Oil Products in Agriculture, 392022 Tambov, Russia \\ ${ }^{2}$ Lipetsk State Technical University, 398055 Lipetsk, Russia \\ ${ }^{3}$ Bauman Moscow State Technical University, 105005 Moscow, Russia
}

\begin{abstract}
Technological parameters and technical level of the equipment at an oil storage facility influence motor fuel's quality and its waste during reception, storage and transfer. The use of intelligent systems during the oil storage and handling process enhances quality preservation and reduction of motor fuel waste caused by evaporation, oxidation and hydration while stored in above-ground horizontal steel tanks. Systems managing "smart" oil-storage facilities combine technologies for on-line collection, transmission and storage of information with instant data processing and analysis, and managerial decision-making techniques. A methodological framework, that includes algorithms and a program with sensors to monitor indicators of an automated horizontal oil reservoir, has been developed to control the technological parameters (temperature, pressure, fuel level) of the tanks during storage of light oil products, and to protect fuel against flooding and evaporation. The application of the neural network forecasting technique for fuel waste from evaporation during storage, and processing of the data array, made it possible to calculate with a $98 \%$ accuracy rate the gasoline waste during storage in horizontal on-ground tanks with up to $100 \mathrm{~m}^{3}$ in volume capacity. The application of a neural network enables development of new fuel storage algorithms and calculation of the optimal storage amount to minimise losses. The concept and developed digital intelligent control solutions for oil storage allows combining data in oil management into a single information space, and to control the automated oil storage system with application of neural networks, deep learning and Big Data.
\end{abstract}

\section{Introduction}

The analysis of light petroleum products in agriculture established the following facts:

- firstly, the solution of food shortages problem is directly related to the growth of technical equipment (tractors, universal machines, combines and cars), that causes a surge in consumption of, primarily, diesel fuel. Agricultural production is one of the main consumers of diesel fuel, whereas in recent years the agro-industrial complex of Russia consumed around 0.8 million tons of gasoline and more than 4.2 million. tonnes of diesel fuels, expert forecast increase of motor fuel consumption in agriculture by 4 times, by 2030, which makes it paramount the problem of meeting the growing needs of agricultural industry in high-quality motor fuel;

- secondly, motor fuel is an expensive resource, the cost of which increases annually in the production of crop production by $15-18 \%$ and accounts for more that $20 \%$ in the structure of the crop's cost composition. During the spring field work of 2018 , the cost of oil products amounted to more than $23 \%$. In particular, prices increased for gasoline with 36,200 rubles/t in 2015 to 46,020 per a tonne in early 2018; diesel fuel (summer type) priced at 32,680 rubles/t in 2015 increased to 43,550 per tonne at the beginning of 2018 . Fuel financial spending during the spring field works in the period from March to July 2018 amounted as it follows: diesel fuel - RUB 70,927.7 million; gasoline RUB 10,117.3 million; agriculture - RUB 62,425.2 million and spare parts - RUB 37,252.0 million.

- thirdly, the research conducted by All-Russian Scientific Research Institute for the Use of Machinery and Oil Products in Agriculture identified a high percentage of defective samples in the total volume of motor fuels used in agriculture (share of nonconforming motor gasoline samples increased from $14 \%$ in 2015 to $17 \%$ in 2017 , diesel fuel from $19 \%$ in 2015 to $35 \%$ in 2017) $[1,2]$.

The quality of motor fuel has a direct impact on its consumption, and, consequently, on the financial cost associated not only with the purchase of motor fuel, but also with the operation of technical equipment in general and environmental pollution.

The preservation and restoration of the motor fuel quality of is one of the most important fundamental scientific problems, and also a cornerstone in ensuring the country's energy, food and environmental security.

Negative impact of evaporation, oxidation and hydration are the main factors in deterioration of motor fuel properties in agriculture. Waste from evaporation and hydration of motor fuel during storage caused by "breathing" of the tanks: handling and transfer of fuel are accompanied by a big "breaths" process, while a storage

* Corresponding author: snagornov@yandex.ru 
process with a small "breath". At the present development stage of motor fuel storage technology it is not possible to avoid such waste, despite a variety of existing methods and technical means for losses reduction. Most of these methods do not have sufficient scientific justification, and use technical means that are obsolete and physically outdated: not adapted to the specific operating conditions of agricultural producers' storage tanks, can not be used to obtain the required motor fuel safety quality indicators due to significant losses from evaporation, have low technical level and do not meet modern environmental requirements.

The solution of the considered problem is possible by introducing intelligent management into the agricultural oil storage facility [3-17].

\section{Materials and methods}

Internet of things, artificial neural networks for deep learning, BigData analysis technologies, Blockchain (a universal tool for building various databases) underpin formation of the "smart" agricultural oil-storage facility concept and its management. The application of these tools tends to change management quality for technological processes and for decision-making at all hierarchy levels, which are based on modern production methods and application of information about the state of controlled system elements and subsystems.

\section{Results and discussion}

The paper presents basic principles and concepts for "smart" and "intelligent" oil storage for agricultural purposes.

The oil storage process encounters various problems that require timely decision making. These problems caused by a number of reasons that are out human control or considerations:

- physical and chemical properties of hydrocarbons;

- environmental influence (changes in air temperature, humidity, speed and direction during transportation and handling, atmospheric pressure, precipitation);

- change in the ratio of the stored motor fuel volume to the total tank volume;

- various negative processes (evaporation of fuel, oxidation, hydration, pollution, etc.) and others.

Based on the estimated volume of motor fuel consumption by Russia's agroindustry complex by 2050 , the volume of natural waste due to evaporation, even according to the existing (conservative) norms, will amount to 80,000 tons for gasoline and 320,000 tons for diesel fuel per annum. Despite the fact that measures against motor fuel waist are the main aim of the energy conservation strategy, up until today the on-land horizontal tanks with a capacity up to $75 \mathrm{~m}^{3}$ that are used in agriculture are not provided neither with theoretical base for waist calculation, nor practically effective devices for waste prevention caused by evaporation and hydration of motor fuel. The choice of devices preventing evaporation losses in on-ground horizontal tanks is associated with the magnitude of such losses; therefore it's important to adequately assess evaporation waste.

In the agriculture environment, the analysis of motor fuel is carried out as an element of a consumption cost whilst being used by tractors and other equipment; petroleum products waste is not analysed in isolation. The lack of sufficient consideration for the equipment's technical condition in the oil storage facilities of the agroindustry complex is one of the main reasons for reduced durability and efficiency of farm equipment that causes overspending of motor fuel, increased effort for maintenance, negative environmental impact during operation and a number of other negative factors. Such trend has been stable for a number of years.

As an example, Table 1 presents evaporation losses volume for AI-92 type gasoline during its one year storage in $25 \mathrm{~m}^{3}$ oil tank that varies depending on the technical condition of the tank and technical state of the supplementary equipment.

Based on the aforementioned facts, it's clear that the development of theoretical frameworks and technical solutions that enable quality preservation and waste prevention of motor fuel due to evaporation, oxidation and rehydration during storage in an on-ground horizontal steel tanks and digital transformation of oil storage facility into a "smart" facility is an important scientific and practical problem that has economic importance. The use of intelligent systems will provide farm producers with a predictive analysis that enables accidents prevention in oil storage facilities and oil product waste, enhances risk management of the oil storage process, increases operation effectiveness in preserving the condition of motor fuel, thereby completely preventing deterioration in its quality [3-10].

Table 1. Comparison of the actual losses of AI-92 type gasoline from evaporation with the norms of natural loss in a $25 \mathrm{~m} 3$ tank

\begin{tabular}{|c|c|c|c|}
\hline $\begin{array}{c}\text { Condition of } \\
\text { the reservoir } \\
\text { and its } \\
\text { equipment }\end{array}$ & $\begin{array}{c}\text { Unpainted, } \\
\text { without oil } \\
\text { fittings, } \\
\text { gaskets, etc }\end{array}$ & $\begin{array}{c}\text { Painted with } \\
\text { a type DK } \\
\text { air valve, } \\
\text { unsealed gas } \\
\text { space, g }\end{array}$ & $\begin{array}{c}\text { Sealed, } \\
\text { painted, with } \\
\text { type DC-M } \\
\text { breathing } \\
\text { valve, RCD }= \\
0.25 \mathrm{~kg} / \mathrm{cm}^{2}\end{array}$ \\
\hline $\begin{array}{c}\text { Small } \\
\text { "breaths", kg }\end{array}$ & 529 & 372 & 53 \\
\hline $\begin{array}{c}\text { Large } \\
\text { "breaths", kg }\end{array}$ & 131 & 88 & 36. \\
\hline $\begin{array}{c}\text { Reverse } \\
\text { "exhale", kg }\end{array}$ & 28 & 19 & 15. \\
\hline $\begin{array}{c}\text { Gas siphon, } \\
\text { blow } \\
\text { moulding }\end{array}$ & 2750 & 530 & - \\
\hline $\begin{array}{c}\text { Total losses, } \\
\mathrm{kg}\end{array}$ & 3565 & 1094 & 104 \\
\hline $\begin{array}{c}\text { Natural losses } \\
\text { norm, kg }\end{array}$ & $\begin{array}{c}\text { Less than } \\
72\end{array}$ & Less than 72 & Less than 72 \\
\hline
\end{tabular}

To resolve the issue, we need cyber-physical systems (mechatronic and robotic systems) capable of discovering new behaviour algorithms in new problem 
situations, as well as finding solutions to the occurring problems. Digital transformation in agriculture and scientific/technological development in the "smart agriculture" filed feature projects with a completely integrated scientific and technical cycles and end-to-end digital systems of the following types [3-17]:

- «smart agricultural enterprise»;

- «smart farm fields»;

- «smart farm»;

- «smart greenhouse»;

- «smart garden».

The authors believe that the inclusion of the "smart" oil storage facility fits the concept of "smart" agriculture and forms a logical part of it.

It is known that the features and attributes of the "smart" environment comprise sensory and information instruments that allow instant collection, accumulation and transmitting of the environment information; whilst the "intellectual" environment - enhances the ability to analyse and make decisions in the managerial procedures for changing environment. In other words, cyberphysical systems should manage the "smart" oil storage facility: to connect the on-line technologies for collection, transmission, and accumulation of information with technologies for instant information processing, analysis and making the right management decisions [11-17].

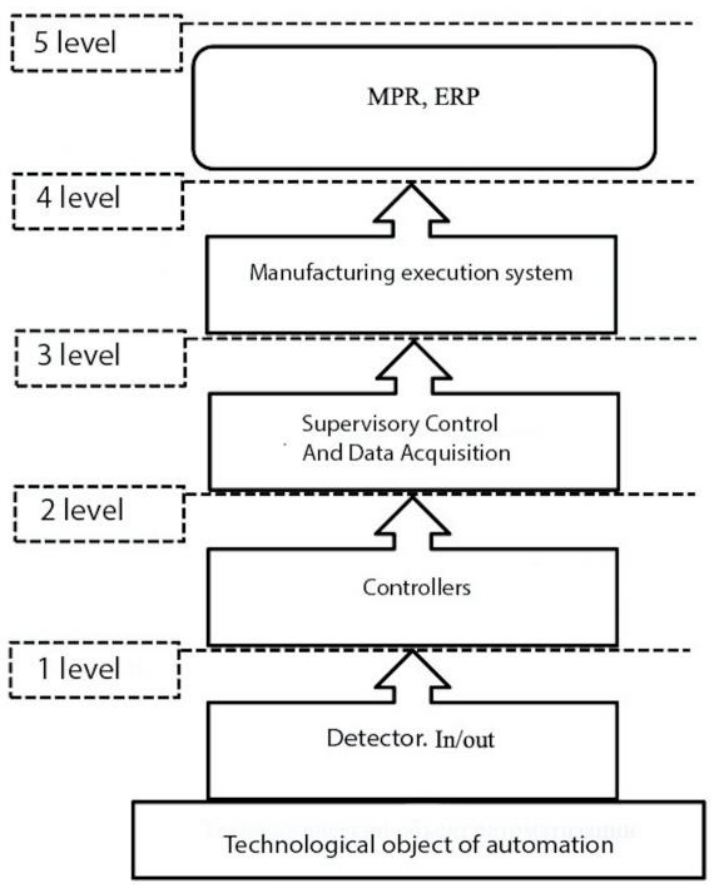

Fig. 1. Classification of automation levels

There are several levels of object automation. There are five levels of automation (figure 1):

1. In/Out-input/output of information or the first level of automation, which includes sensors that transmit information about the parameters of the object;

2. Control-data collection and direct control of the robotic system, sensors, is the second level of automation;
3. SCADA - the third level of automation of the facility, which includes a computer program for collecting information and Supervisory control of the facility, operational process control;

4. MES - production execution system, technology management is the fourth level of automation;

5. MPR, ERP - the fifth level of planning and resource management of the entire enterprise.

The essential conditions for functioning of the "smart" oil storage are as follows:

- Informatization of all processes carried out at the oil storage facility using BigData techniques;

- minimization of uncertainties, including that caused by a "human" factor;

- consideration of a region's natural and climatic conditions.

A methodological framework was developed to control the technological parameters of oil tanks (temperature, pressure, fuel level) during storage of light oil products, and to manage the protection system that counters hydration and evaporation of fuel. The framework includes algorithms and a program with sensors to monitor indicators for an automated control of horizontal tanks at the oil storage field. Readings from the sensors are stored in the database. The database acts as an information source for live assessment and prediction of fuel quality in the tank using a neural network.

The program controls a controller that switches on flooding and evaporation prevention system for the fuel. When the pressure of the "inhale" breathing valve reaches the pre-determined point in the tank, the controller triggers the system to protect the stored fuel from hydration from the atmospheric moisture. When the pressure of the "exhalation" breathing valve reaches the pre-determined point in the tank, the controller triggers the system to protect the stored fuel from evaporation. The algorithm is developed for the in-tank accidents prevention program and for preservation of the stored fuel quality with the ability to pre-set the indicators and probability threshold prior to a critical event. This is done for timely indication about the problem or to activate quality preservation mechanism.

In order to control the automated oil storage facility and render trial-runs of neural networks, it has become necessary to maintain a database to keep the data. This is relevant for both incoming information, used for system learning, and output information, used to adjust the work of artificial intelligence. Data in the database-a should contain the following details - description of the oil reservoir field, for each tank - its current state, fuel level, temperature, pressure, etc., a table with calculated thresholds for activating the protection device to counter hydration and evaporation, tank calibration (calculation of fuel volume depending on its level) $[18,19]$.

With application of the accumulated information array in conjunction with a neural network, a fuel waste prediction technique has been developed and applied. To interpret the dependence of fuel evaporation during storage from the environmental conditions, the size of the 
tank and the volume of gasoline contained within, a basic neural network equation was established as follows:

$$
G=F\left(W_{R} * R+W_{m} * M+\Sigma W_{\Psi} * \Psi\right),
$$

$\Psi$ is a vector of environment variables; $\mathrm{R}$ a vector of reservoir parameters; $\mathrm{M}$ is the fuel mass in the tank $(\mathrm{kg})$; $W_{R}, W_{m}, W_{\Psi}$ - vectors of weight coefficients of the tank, mass of the fuel and of the environment respectively; $\mathrm{F}$ is the neuron activation function. In the work of selected hyperbolic tangent as the activation function of neuron $y=a \cdot \operatorname{th}(b x)$ where $\mathrm{a}$ and $\mathrm{b}$ are constants $(\mathrm{a}=1,7159$ and $b=2 / 3)$. This activation function can describe nonlinear processes.

口After trial-testing of the constructed neural network, the results of its operation and evaporation calculation were compared with experimental results. It is shown that the neural network can calculate the waist during storage of gasoline in a horizontal on-ground with up-to $100 \mathrm{~m} 3$ capacity reservoirs achieving a 98\% accuracy rate. With application of a neural network, it is possible to simulate the fuel storage scenarios and calculate the most optimal storage volume with minimal losses.

At the same time, neural networks are also used to manage the risks associated with fuel storage. Application of the neural network method allowed determining the range of temperatures, pressures in the form of an n-dimensional parallelepiped. The discovered ranges estimate the risk probability [19].

Figure 2 presents a graph that demonstrates comparison of calculated and actual gasoline losses during storage due to evaporation for different load scenarios in the $3 \mathrm{~m} 3$ capacity tank located in the average climate region.

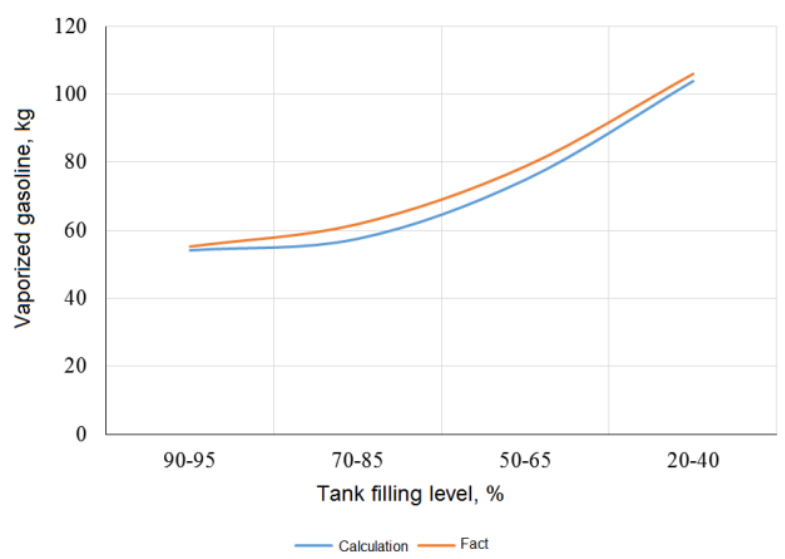

Fig. 2. Comparison of calculated and actual gasoline losses during storage due to evaporation for different load scenarios in the $3 \mathrm{~m}^{3}$ capacity tank located in the average climate region.

\section{Conclusion}

With vast practical experience in operating neural networks, an algorithm was formalised for election of the neural network's architecture fit for solving practical problems.

The concept of an automated agricultural oil storage facility was developed that enables accidents prevention in the storage field, identifies and pre-warns about such unfavourable events as fuel leak, failure of a respiratory valve, fuel combustion, enhances fuel quality preservation and prevents losses of motor fuel caused by evaporation, oxidation and rehydration during storage in an on-ground horizontal tanks.

Application of the concept will make it possible to combine data about the oil industry into a single information space, and to control the automated oil storage system using neural networks and Big Data.

In conclusion, we note that the oil tank can be called "smart" only when its control system is able to develop new algorithms for the storage of motor fuel, and it is designed in accordance with the system laws.

\section{References}

1. Agro-industrial complex in 2017 (Rosinformagrotekh, Moscow, 2018)

2. P.A. Chekmarev, About the state of machine-tractor Park, improvement of work of engineering and technical services of agrarian and industrial complex and tasks within implementation of the State program for 2013-2020, Retrieved from: http://irkobl.ru/sites/agroline/ 02 Chekmarev 31_01 \%D0\%98\%D1\%82\%D0\%B E\%D0\%B3_.pdf.

3. V. Chernoivanov, Digital Technologies in Agrobusiness, Machinery and Equipment for Rural Area, 5, 2-4 (2018)

4. V. Chernoivanov, Possibilities of Applications of Intelligent Systems in Designing New Generation Machines, Machinery and Equipment for Rural Area, 1, 2-4 (2015)

5. V. Chernoivanov, Scientific Approaches to Substantiation of Necessity to Intellectualize Machines, Machinery and Equipment for Rural Area, 9, 2-5 (2014)

6. V. Yakushev, Digital technologies of precision farming in implementation of smart farming priority of Russian, Bulletin of the Russian agricultural sciences, 2, 11-15 (2019)

7. D. Belyh, The use of smart technologies in agriculture on the smart agriculture convergent platform, Ways to improve the efficiency of irrigated agriculture, 1(69), 89-94 (2018)

8. T. Eldieva, Smart innovation trends in agriculture, Int. Agricultural J., 6, 46-49 (2018)

9. V. Yakushev, Prospects of "smart agriculture" in Russia, Bulletin of the Russian agricultural sciences, 9, 773-784 (2018)

10. F. Privalov, "Smart" machines and lean technology - future of agriculture, The Science and Innovations, 9(139), 70-72 (2014)

11. A. Tuskov, BIG DATA technology as a tool to improve the efficiency of agricultural enterprises, Drukerovskij bulletin, 3(23), 153-162 (2018)

12. K. Mefod'eva, Digital data in business turnover by the example of the application of Internet of things 
in agrarian sphere: legal aspects, Agrarian and land law, 8(164), 143-148 (2018)

13. A. Shuvalov, Application of internet of things technology for sustainable agriculture, Synergy of Sciences, 30, 821-829 (2018)

14. G. Adilova, Scientific and methodological foundations of the formation of the digital economy system in agriculture of Uzbekistan, Theoretical \& Applied Science, 2(70), 274-277 (2019)

15. B. Runov, The use of robotic tools in agriculture, Agrotechnics and energy supply, 4(8), 6-14 (2015)
16. G. Perotina, Network security in the Internet of things, Automation, communication and Informatics, 3, 33-34 (2019)

17. S. Vecherskaya, Prospects of the implementation of the internet of things in the agribusiness, Veles, 91(63), 42-47 (2018)

18. M. Levin, Concept of virtually cloud system of automation of reservoir park, Science in the central Russia, 5(35), 82-88 (2018)

19. M. Levin, Risk management storage light oil products from application of neural networks, Science in the Central Russia, 1(25), 79-86 (2017) 